\title{
NICD inhibits cell proliferation and promotes apoptosis and autophagy in PC12 cells
}

\author{
BO LI ${ }^{1}$, PING DUAN ${ }^{1}$, XUEFEI HAN ${ }^{2}$, WENHAI YAN ${ }^{3}$ and YING XING $^{1}$ \\ ${ }^{1}$ Department of Physiology, Zhengzhou University, Zhengzhou, Henan 450001; \\ ${ }^{2}$ Stem Cell Research Center, Zhengzhou University, Zhengzhou, Henan 450052; \\ ${ }^{3}$ Department of Pathophysiology, Zhengzhou University, Zhengzhou, Henan 450001, P.R. China
}

Received May 31, 2016; Accepted April 10, 2017

DOI: $10.3892 / \mathrm{mmr} .2017 .6878$

\begin{abstract}
Pheochromocytoma is a tumor of the adrenal medulla for which surgical resection is the only therapy. Though the Notch1 signaling pathway has been suggested as a target for pheochromocytoma treatment, the effect of Notch1 intracellular domain (NICD) on pheochromocytoma cell growth remains unknown. In the present study, the effect of NICD on pheochromocytoma cell growth was examined, by use of a tetracycline-inducible system for NICD overexpression in the PC12 pheochromocytoma cell line. Flow cytometry was used to determine the effect of NICD on cell cycle phase distribution and apoptosis in PC12 cells. Protein expression levels of microtubule associated protein 1 light chain 3 B (LC3B), Beclin 1, autophagy-related (ATG) 5 and ATG7 were examined using western blot analysis. Untreated PC12 cells lack NICD expression, while treatment with doxycycline resulted in a significant NICD overexpression. NICD overexpression promoted cell apoptosis and suppressed cell proliferation via regulating S-phase arrest. In addition, NICD overexpression stimulated the expression of autophagy-related proteins LC3B, Beclin 1, ATG5 and ATG7. In conclusion, NICD promoted cell apoptosis, suppressed cell proliferation, and stimulated autophagy-related protein expression in $\mathrm{PC} 12$ cells. The present data indicate that overexpression of NICD may be a promising potential therapy for pheochromocytoma.
\end{abstract}

Correspondence to: Dr Wenhai Yan, Department of Pathophysiology, Zhengzhou University, 100 Science Avenue, High-Tech Zone, Zhengzhou, Henan 450001, P.R. China

E-mail:yanwh@zzu.edu.cn

Dr Ying Xing, Department of Physiology, Zhengzhou University, 100 Science Avenue, High-Tech Zone, Zhengzhou, Henan 450001, P.R. China

E-mail: xingy@zzu.edu.cn

Key words: Notch1 intracellular domain, Notch1, apoptosis, proliferation, autophagy, pheochromocytoma

\section{Introduction}

Although the incidence of pheochromocytoma is only two cases per million of the global population (1), it leads to hypertension and life-threatening cardiovascular complications (2). Pheochromocytoma, located in the adrenal medulla, is a chromaffin cell neoplasm that secretes catecholamines and various hormones, including norepinephrine, epinephrine, dopamine, and chromogranin A. These vasoactive hormones are responsible for the classical triad of symptoms in pheochromocytoma: Episodic headache, sweating, and palpitations (3). Due to the catecholamine-secreting nature of pheochromocytomas, the diagnostic biochemical tests for these tumors involve detection of these hormones. However, no effective treatment exists for this tumor. With drug therapy having no significant long-lasting benefit, operative treatment is the only definitive cure $(4,5)$. Therefore, it is important to explore the mechanism underlying pheochromocytoma pathogenesis and to investigate novel and improved treatment methods for pheochromocytomas.

The Notch1 signaling pathway is a highly-conserved pathway that serves important roles in cell fate specification, differentiation, proliferation and survival (6-8). Notch1 is a transmembrane receptor protein that is activated by binding to the delta-like protein 1 ligand, which results in a double proteolytic cleavage of the Notch1 protein (9). The first proteolytic cleavage is mediated by a metalloprotease in the Notch extracellular domain, followed by the second cleavage by the $\gamma$-secretase complex in the transmembrane domain. Notch1 intracellular domain (NICD) then translocates from the cytoplasm to the nucleus and binds with the recombination signal binding protein for immunoglobulin $\kappa \mathrm{J}$ region and other DNA binding complexes to regulate expression of genes, including hes family bHLH transcription factor 1 (HES1), cyclin D and hes related family bHLH transcription factor with YRPW motif 1 (10,11). Pheochromocytoma cells do not express active Notch1, but Notch1 activators, valproic acid and suberoyl bis-hydroxamic acid, have been reported to inhibit growth and limit hormonal secretion by pheochromocytoma cells (12). However, the function of NICD in pheochromocytoma cells remains unclear.

In order to investigate the role of NICD in pheochromocytoma, a tetracycline-inducible system for NICD overexpression in the PC12 pheochromocytoma cell line was employed. The 
present study tested the hypothesis that overexpression of NICD in PC12 cells may influence tumor cell growth.

\section{Materials and methods}

Cell culture. Rat $\mathrm{PC} 12$ cells were cultured in a humidified atmosphere of $5 \% \mathrm{CO}_{2}$ at $37^{\circ} \mathrm{C}$ in high-glucose Dulbecco's modified Eagle's medium (DMEM; Sigma-Aldrich; Merck KGaA, Darmstadt, Germany), supplemented with $10 \%$ fetal calf serum (HyClone; GE Healthcare Chicago, IL, USA), $100 \mathrm{U} / \mathrm{ml}$ penicillin and $100 \mathrm{mg} / \mathrm{ml}$ streptomycin. Cells were subcultured every 2-3 days. The control and PC12-NICD cell lines were constructed by stable transfection of the tet-on-EGFP and tet-on-EGFP-NICD plasmids respectively, as described previously (13).

Cell morphology observation. PC12 cells were treated with $500 \mu \mathrm{g} / \mathrm{ml}$ doxycyclin (Dox) for $36 \mathrm{~h}$ at room temperature and cell nuclei were stained with DAPI at 0 and $36 \mathrm{~h}$. The cells were then observed using an inverted fluorescence microscope (IMT-2; Olympus Corporation, Tokyo, Japan) and cell images were captured using a charge-coupled device camera attached to the microscope.

Flow cytometry. Cells were cultured and treated with Dox for $36 \mathrm{~h}$. Cells were then trypsinized, washed twice with PBS, and incubated with phycoerythrin (PE)-conjugated monoclonal anti-Notch1 antibody (cat. no. 559763; 1:50; BD Biosciences, Franklin Lakes, NJ, USA), which can also recognize NICD, for $30 \mathrm{~min}$ at $4^{\circ} \mathrm{C}$ in the dark. The cells were washed twice with PBS, fixed with $4 \%$ formaldehyde in PBS and centrifuged. Cells were analyzed using a FACSCanto II (BD Biosciences). A $488 \mathrm{~nm}$ wavelength laser was used to excite enhanced green fluorescent protein (EGFP) and PE and fluorescence signal was acquired on the FL1 and FL2 spectral detection channels, respectively. Results were analyzed with BD FACS Data-Interpolating Vibrational Analysis software version 5.0 (BD Biosciences).

Apoptotic cells detection. Apoptosis was detected by Annexin V-Phycoerythrin (PE) and 7-Amino-Actinomycin (7-AAD) staining followed by flow cytometric analysis. The staining was preformed using an Annexin V-PE Apoptosis Detection kit (cat. no. 559763; BD Biosciences), following the manufacturer's protocol. The cells were resuspended in $400 \mu \mathrm{l}$ $1 \mathrm{X}$ binding buffer at a concentration of $1 \times 10^{6} \mathrm{cells} / \mathrm{ml}$, and then incubated with $5 \mu \mathrm{l}$ Annexin V-PE and $5 \mu 1$ 7-AAD for $15 \mathrm{~min}$ at room temperature in the dark. Finally, the cells were analyzed by flow cytometry.

Cell cycle assay. Cell cycle phase distribution was assessed in order to evaluate cell proliferation in PC12 cells. Cells $\left(1 \times 10^{6}\right)$ were collected and washed with ice-cold PBS, then fixed in ice-cold $70 \%$ ethanol at $-20^{\circ} \mathrm{C}$ for $24 \mathrm{~h}$. The fixed cells were centrifuged at $1,000 \times \mathrm{g}$ for $5 \mathrm{~min}$, washed twice with PBS, resuspended in PBS and incubated with $500 \mu 1 \mathrm{PI}$ (cat. no. 550825; BD Biosciences) at $4^{\circ} \mathrm{C}$ for $30 \mathrm{~min}$. Finally, the cells were analyzed by flow cytometry.

Western blotting. Following washing with cold PBS three times, cells were lysed in radioimmunoprecipitation assay buffer $(150 \mathrm{mM} \mathrm{NaCl}, 10 \mathrm{mM}$ Tris- $\mathrm{HCl} \mathrm{pH}$ 7.4, $0.5 \%$ Triton $\mathrm{X}-100$ and protease inhibitors; Merck KGaA), homogenized on ice, and centrifuged at $12,000 \mathrm{xg}$ at $4^{\circ} \mathrm{C}$ for $15 \mathrm{~min}$. The supernatant was collected and stored at $-80^{\circ} \mathrm{C}$ until use. Protein concentration was determined using a bicinchoninic acid assay kit (Pierce; Thermo Fisher Scientific, Inc., Waltham, MA, USA). Total proteins (25 $\mu \mathrm{g})$ were separated on $12 \%$ tris-polyacrylamide gel. The proteins were then transferred to nitrocellulose membranes (EMD Millipore, Billerica, MA, USA). The membranes were blocked in 5\% non-fat dry milk for $1 \mathrm{~h}$ at $37^{\circ} \mathrm{C}$, washed in TBS with $0.05 \%$ Tween-20 (TBST) and incubated overnight with mouse primary antibodies targeting microtubule associated protein 1 light chain 3 B (LC3B), Beclin1, autophagy-related (ATG)5 and ATG7 (cat. nos. 3868, 3495, 12994 and 8558; 1:1,000; Cell Signaling Technology, Inc., Danvers, MA, USA;) at $4^{\circ} \mathrm{C}$. Mouse anti- $\beta$-actin (cat. no. sc-47778, 1:1,000; Santa Cruz Biotechnology, Inc., Dallas, TX, USA.) was used as an internal control. The membranes were washed thrice in TBST and incubated for $1 \mathrm{~h}$ with secondary antibodies conjugated to horseradish peroxidase (HRP) (cat. no. SC-2004; 1:2,000; Santa Cruz Biotechnology, Inc.) at $37^{\circ} \mathrm{C}$, washed thrice in TBST, and treated with Immun-Star HRP peroxide buffer and Luminol/Enhancer (Beijing Zhongshan Golden Bridge Biotechnology Co., Ltd., Beijing, China) for chemiluminescent detection of protein bands. The computer gray-scale value was analyzed using Quantity One software version 4.6.2 (Bio-Rad Laboratories, Inc., Hercules, CA, USA).

Statistical analysis. Data were analyzed using SPSS 16.0 software (SPSS, Inc., Chicago, IL, USA) and were presented as the mean \pm standard deviation. Significance analysis was performed using Student's t-test. $\mathrm{P}<0.05$ was considered to indicate a statistically significant difference.

\section{Results}

Dox treatment induces NICD expression in PC12 cells. A tetracycline (tet)-inducible system was used to drive overexpression of NICD in PC12 cells. PC12 cells were transfected with either a tet-on-EGFP plasmid (control) or a NICD-expressing tet-on-EGFP-NICD plasmid (NICD), and protein expression was then induced with Dox. EGFP fluorescence was assessed in the Dox-induced PC12 cells at $36 \mathrm{~h}$ and it was observed that $90.4 \%$ of the total cells were EGFP-positive in the NICD group (Fig. 1A). Next, NICD expression was examined by staining with a PE-conjugated specific antibody and flow cytometry analysis. PE fluorescence was significantly enhanced following induction with Dox for $36 \mathrm{~h}$ (Fig. 1B and C). These results establish that NICD was overexpressed in the PC12-NICD cells at $36 \mathrm{~h}$ post-induction with Dox.

Overexpression of NICD increases PC12 cell apoptosis. To investigate the effect of NICD overexpression on apoptosis, $\mathrm{PC} 12$ cells were induced with Dox for $36 \mathrm{~h}$ and then double-stained with Annexin V and PI prior to flow cytometry analysis. PC12 cells in which NICD was overexpressed exhibited an increased apoptosis rate compared with control cells (Fig. 2).

Overexpression of NICD inhibits PC12 cell proliferation. To investigate the effect of NICD overexpression on PC12 cell 

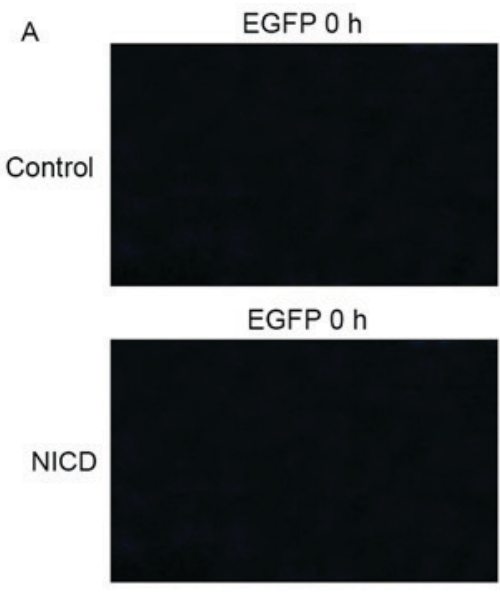

B

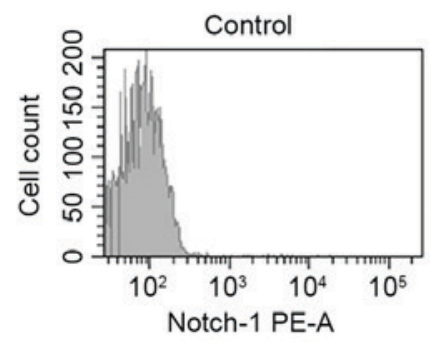

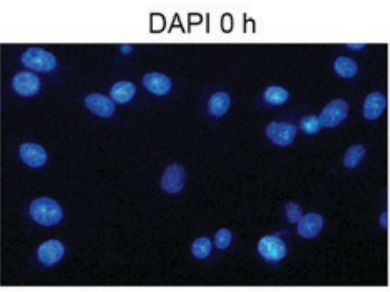

DAPI $0 \mathrm{~h}$
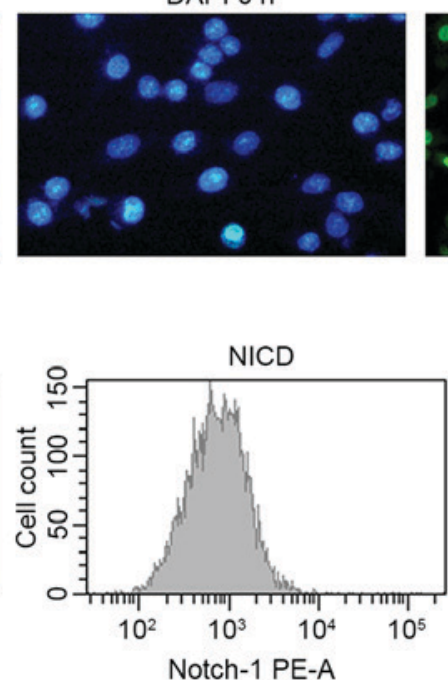

EGFP $36 \mathrm{~h}$

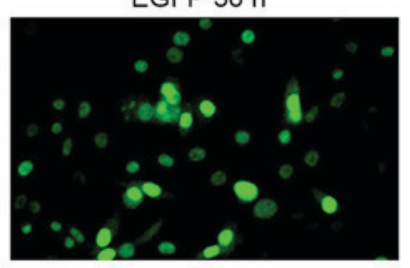

EGFP $36 \mathrm{~h}$

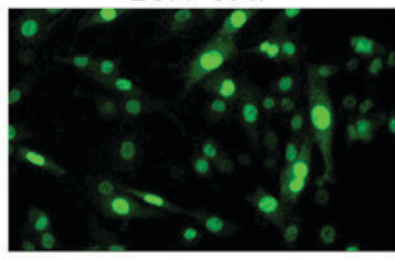

C

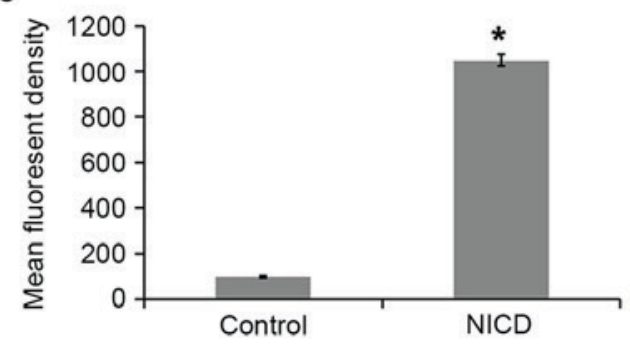

Figure 1. NICD overexpression in PC12 cells. PC12 cells were transfected with tet-on-EGFP-NICD (NICD) or tet-on-EGFP (control) plasmids, then expression was induced by doxycycline treatment for $36 \mathrm{~h}$. (A) EGFP fluorescence (green) was observed by fluorescence microscopy at 0 and $36 \mathrm{~h}$ post-induction. DAPI was used as a nuclear counterstain (blue); magnification, x100. (B) Expression of the NICD protein was detected by staining with a PE-conjugated specific antibody and flow cytometry in the control and NICD groups at $36 \mathrm{~h}$ post-induction. (C) Quantification of Notch1-PE fluorescence signal density in the control and NICD groups. "P<0.05 ( $\mathrm{n}=6)$. NICD, Notch1 intracellular domain; EGFP, enhanced green fluorescent protein; tet, tretracycline; PE, phycoerythrin.
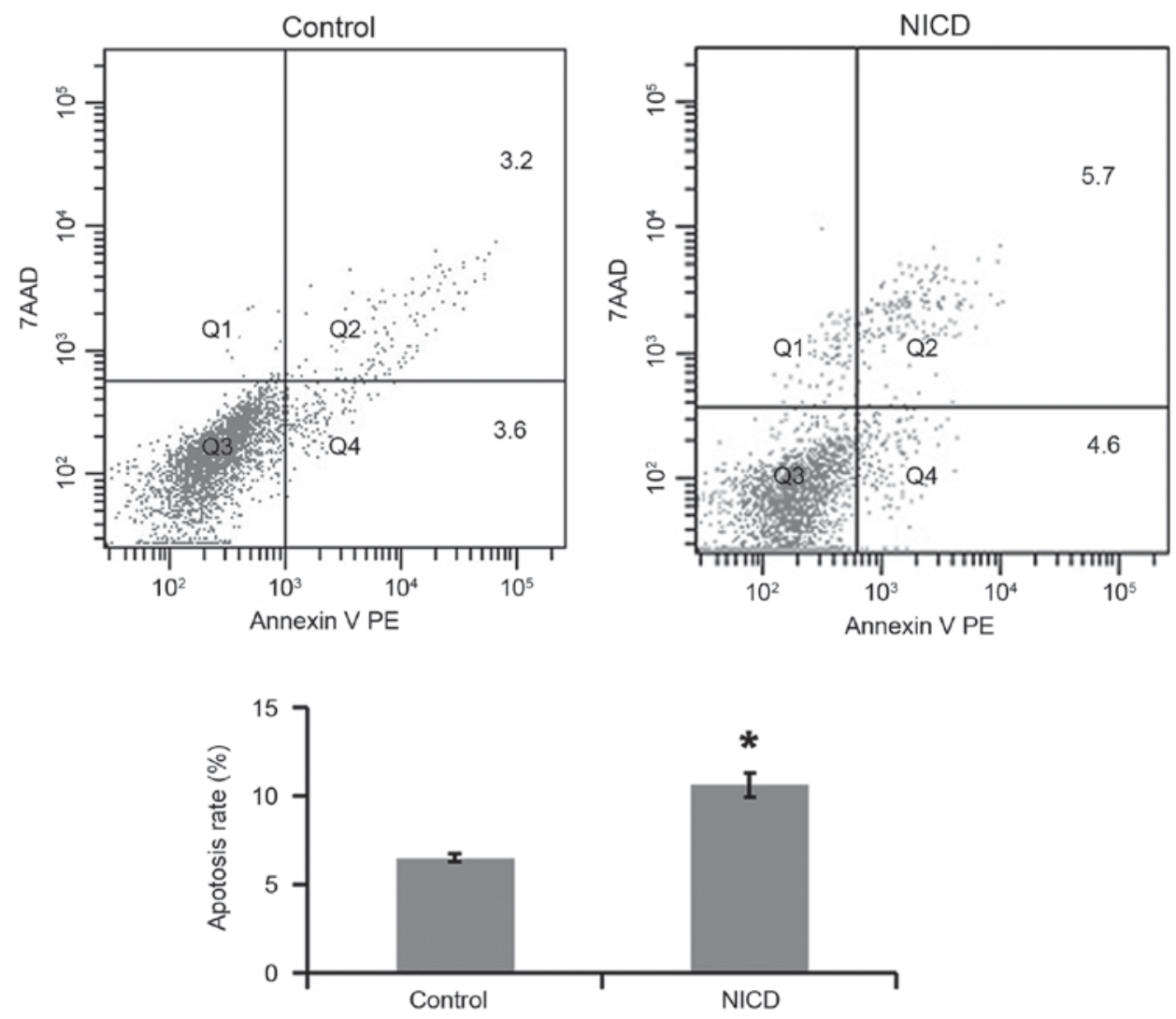

Figure 2. Overexpression of NICD promotes cell apoptosis in PC12 cells. Apoptosis was analyzed by flow cytometry at $36 \mathrm{~h}$ post- doxycycline induction in the control and NICD groups. Cells were stained with PE-conjugated Annexin V and 7AAD. Representative plots and quantification of \% apoptotic cells (Q2 + Q4 quadrants in the plots). ${ }^{*} \mathrm{P}<0.05$ ( $\mathrm{n}=6$ ). NICD, Notch1 intracellular domain; $\mathrm{PE}$, phycoerythrin. 

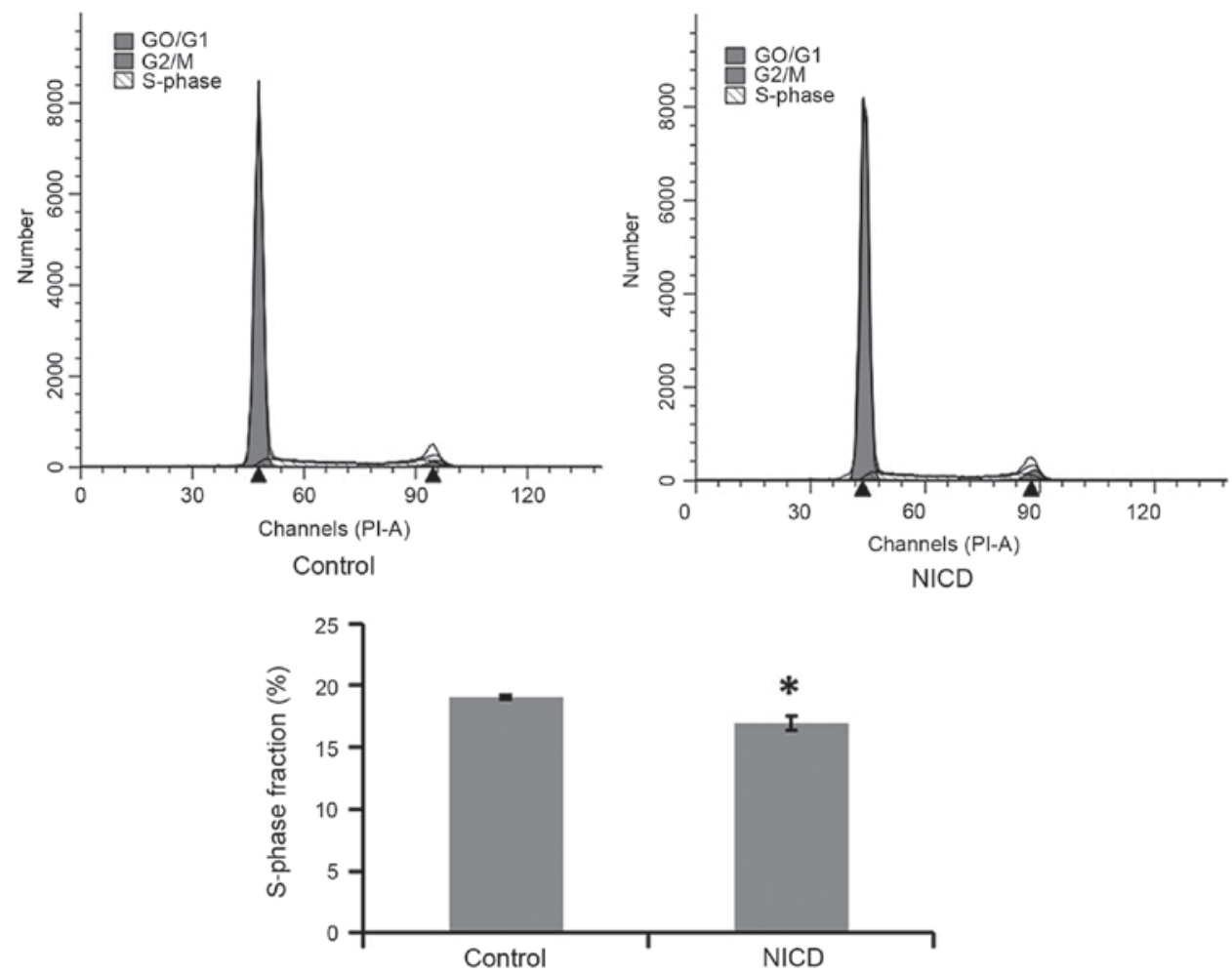

Figure 3. Overexpression of NICD suppresses cell proliferation in PC12 cells. Cell cycle phase distribution analysis was performed by PI staining and flow cytometry at $36 \mathrm{~h}$ post-doxycycline induction in the control and NICD groups. Representative plots and quantification of the \% of cells in the S-phase of the cell cycle. ${ }^{*} \mathrm{P}<0.05$ ( $\left.\mathrm{n}=6\right)$. NICD, Notch1 intracellular domain; PI, propidium iodide.

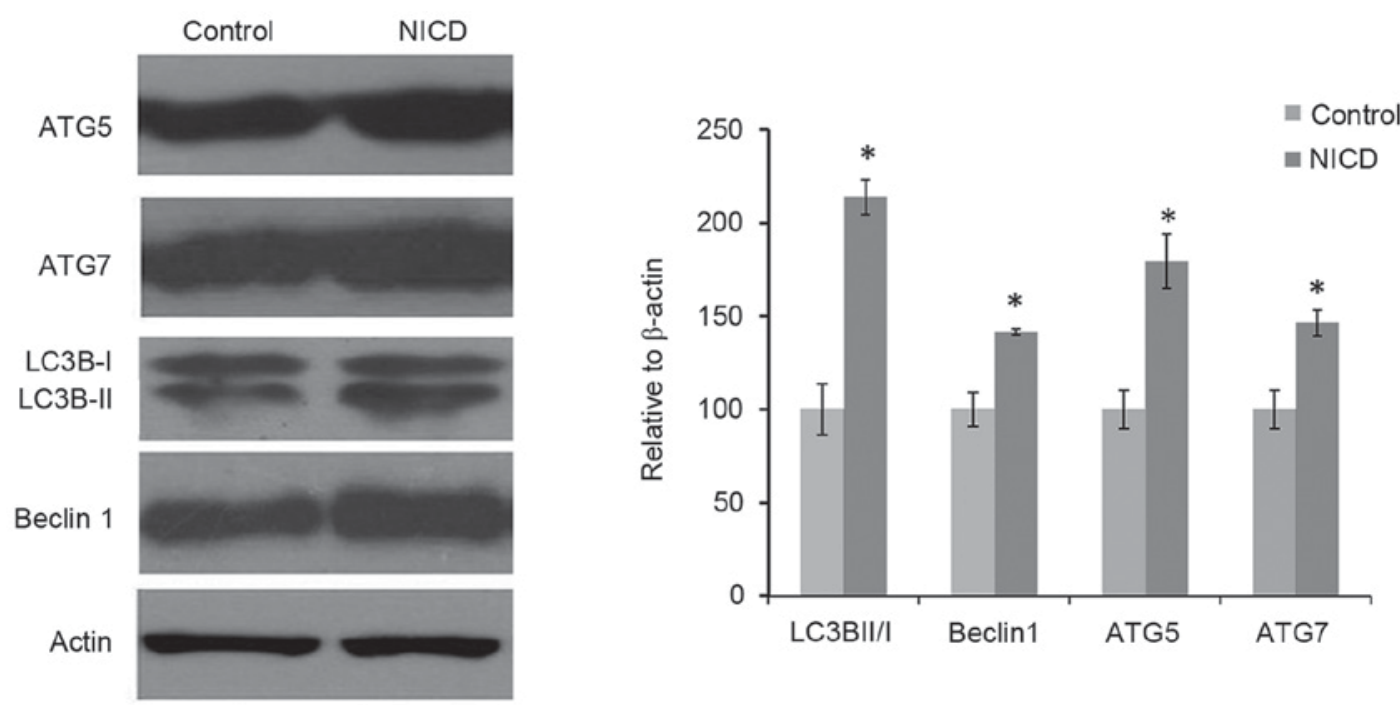

Figure 4. Overexpression of NICD influences autophagy-related protein expression in PC12 cells. Expression levels of autophagy-related protein ATG5, ATG7, LC3B and Beclin1 were detected by western blot analysis in the control and NICD groups at $36 \mathrm{~h}$ post-doxycycline induction. Representative blots and quantification of protein levels normalized to $\beta$-actin. "P<0.05 ( $\mathrm{n}=6)$. NICD, Notch1 intracellular domain; ATG, autophagy-related; LC3B, microtubule associated protein 1 light chain $3 \mathrm{~B}$.

proliferation, cell cycle analysis was performed. PC12 cells were induced with Dox for $36 \mathrm{~h}$, stained with PI and then analyzed by flow cytometry for cell cycle phase distribution. The results indicated that the \% of cells in the S-phase of the cell cycle was suppressed in the NICD group compared with the control group, which suggested that NICD overexpression significantly inhibited the growth of $\mathrm{PC} 12$ cells via regulating S-phase cell cycle arrest (Fig. 3).
NICD overexpression influences autophagy-related protein expression. To evaluate the effect of NICD on autophagy, the protein expression levels of autophagy-related proteins ATG5, ATG7, LC3B and Beclin1 were analyzed by western blotting in cells that were induced with Dox for $36 \mathrm{~h}$. The results demonstrated that Dox-induced NICD expression significantly increased the level of LC3II/I ratio, and the expression levels of ATG5, ATG7 and Beclin1 compared with the group (Fig. 4). 
These results suggested that NICD may be involved in regulating PC12 cell growth in part through autophagy-dependent pathways.

\section{Discussion}

Notch signaling served an important role in cell fate specification, differentiation, proliferation, and survival (14). Previous studies have demonstrated that Notch signaling is significant in neurogenesis (15). Increased expression of active Notch1 protein inhibits cell growth and hormone secretion in carcinoid norepinephrine tumors and medullary thyroid cancer cells $(16,17)$, and Notch1 activator/histone deacetylase inhibitor compounds lead to a decrease in proliferation in PC12 cells (12). In another study, treatment with the Notch1 signaling pathway inhibitor $\mathrm{N}$-[N-(3,5-difluorophenacetyl)-Lalanyl]-S-phenylg lycinet-butyl ester and with the amyloid- $\beta$ peptide 25-35, resulted in prolonged survival and decreased expression of caspase 3,8 and 9 in PC12 cells (18). However, the function of NICD in pheochromocytoma remains unknown.

In order to explore the role of NICD in pheochromocytoma, a tet-inducible system for NICD expression in the PC12 cell line was used. Through transfection and drug selection, PC12 cells expressing tet-inducible NICD (PC12-NICD cells) were obtained, in which NICD expression is under a tight regulation by Dox (13). At $36 \mathrm{~h}$ post-Dox induction, NICD protein expression levels were significantly enhanced in the PC12-NICD cells compared with the control cells. The results demonstrated that NICD overexpression suppressed cell proliferation and increased the rate of apoptosis in PC12 cells.

Autophagy is an intracellular degradation system that delivers proteins and organelles to the lysosome and provides cells with nutrients by recycling the degradation products (19-21). Mutants of the Notch gene, $g l p-1$, lead to inhibition of germline proliferation and to increase in autophagy levels in the nematode Caenorhabditis elegans $(22,23)$. Another study on T-cell leukemia reported that activation of the Notch target gene HES1 regulates the expression of phosphatase and tensin homolog (24). Inhibition of Notch signaling increases autophagy activity. Autophagy has been reported to occur downstream of the Notch pathway receptor activation during Drosophila melanogaster zygote development, and a decrease in autophagy resulted in precocious activation of Notch signaling in ovarian follicle cells (25). These studies suggest a link between Notch signaling and autophagy, that remains to be elucidated. In the present study, expression levels of autophagy-related proteins LC3B, ATG5, ATG7 and Beclin 1 were significantly increased in PC12 cells following overexpression of NICD, which implied that NICD, a fragment of the Notch1 protein, is sufficient to induce autophagy in PC12 cells. Whether NICD-mediated autophagy contributes to suppressed cell proliferation and increased apoptosis needs to be further explored in the future. Recently, Wu et al (26) reported that developmental retention of early-stage cells and the differentiation of stem cells is delayed in the Atg16L1 mutation mouse model, which suggests that autophagy regulates Notch degradation and modulates stem cell development and neurogenesis.

In summary, the present study indicated that overexpression of NICD suppressed cell proliferation, promoted cell apoptosis, and activated increased autophagy-realted protein expression in PC12 cells. The present results suggest that NICD may be a promising target towards developing novel and effective treatment strategies against pheochromocytoma.

\section{Acknowledgements}

The present study was funded by the National Natural Science Foundation of China (grant nos. 31100790 and 81171250).

\section{References}

1. Fung MM, Viveros $\mathrm{OH}$ and O'Connor DT: Diseases of the adrenal medulla. Acta Physiol (Oxf) 192: 325-335, 2008.

2. Eisenhofer G: Screening for pheochromocytomas and paragangliomas. Curr Hypertens Rep 14: 130-137, 2012.

3. Lenders JW, Duh QY, Eisenhofer G, Gimenez-Roqueplo AP, Grebe SK, Murad MH, Naruse M, Pacak K and Young WF Jr; Endocrine Society: Pheochromocytoma and paraganglioma: An endocrine society clinical practice guideline. J Clin Endocrinol Metab 99: 1915-1942, 2014.

4. Adler JT, Mack E and Chen H: Isolated adrenal mass in patients with a history of cancer: Remember pheochromocytoma. Ann Surg Oncol 14: 2358-2362, 2007.

5. Adler JT, Meyer-Rochow GY, Chen H, Benn DE, Robinson BG Sippel RS and Sidhu SB: Pheochromocytoma: Current approaches and future directions. Oncologist 13: 779-793, 2008.

6. Qi S, Zhao X, Li M, Zhang X, Lu Z, Yang C, Zhang C, Zhang H and Zhang N: Aberrant expression of Notch1/numb/snail signaling, an epithelial mesenchymal transition related pathway, in adenomyosis. Reprod Biol Endocrinol 13: 96, 2015.

7. Kangsamaksin T, Tattersall IW and Kitajewski J: Notch functions in developmental and tumour angiogenesis by diverse mechanisms. Biochem Soc Trans 42: 1563-1568, 2014

8. Capaccione KM and Pine SR: The Notch signaling pathway as a mediator of tumor survival. Carcinogenesis 34: 1420-1430, 2013.

9. Penton AL, Leonard LD and Spinner NB: Notch signaling in human development and disease. Semin Cell Dev Biol 23: 450-457, 2012.

10. Guruharsha KG, Kankel MW and Artavanis-Tsakonas S: The Notch signalling system: Recent insights into the complexity of a conserved pathway. Nat Rev Genet 13: 654-666, 2012.

11. Hori K, Sen A and Artavanis-Tsakonas S: Notch signaling at a glance. J Cell Sci 126: 2135-2140, 2013.

12. Adler JT, Hottinger DG, Kunnimalaiyaan M and Chen H: Histone deacetylase inhibitors upregulate Notch-1 and inhibit growth in pheochromocytoma cells. Surgery 144: 956-962, 2008.

13. Liu YM, Duan P, Huang CT, Li B, Han XF, Xu Y, Yan WH and Xing Y: Construction of inducible lentiviral vector containing human Notch1 and EGFP gene and its expression in PC12 cells. Zhongguo Ying Yong Sheng Li Xue Za Zhi 29: 232-237, 2013 (In Chinese).

14. Louvi A and Artavanis-Tsakonas S: Notch and disease: A growing field. Semin Cell Dev Biol 23: 473-480, 2012.

15. Kong L, Hu Y, Yao Y, Jiao Y, Li S and Yang J: The coumarin derivative osthole stimulates adult neural stem cells, promotes neurogenesis in the hippocampus, and ameliorates cognitive impairment in APP/PS1 transgenic mice. Biol Pharm Bull 38: 1290-1301, 2015.

16. Kunnimalaiyaan M, Vaccaro AM, Ndiaye MA and Chen $\mathrm{H}$ : Overexpression of the NOTCH1 intracellular domain inhibits cell proliferation and alters the neuroendocrine phenotype of medullary thyroid cancer cells. J Biol Chem 281: 39819-39830, 2006.

17. Nakakura EK, Sriuranpong VR, Kunnimalaiyaan M, Hsiao EC Schuebel KE, Borges MW, Jin N, Collins BJ, Nelkin BD, Chen H and Ball DW: Regulation of neuroendocrine differentiation in gastrointestinal carcinoid tumor cells by notch signaling. J Clin Endocrinol Metab 90: 4350-4356, 2005.

18. Liang H, Zhang Y, Shi X, Wei T and Lou J: Role of Notch-1 signaling pathway in PC12 cell apoptosis induced by amyloid beta-peptide (25-35). Neural Regen Res 9: 1297-1302, 2014.

19. Levine B and Klionsky DJ: Development by self-digestion: Molecular mechanisms and biological functions of autophagy. Dev Cell 6: 463-477, 2004.

20. Mizushima N, Levine B, Cuervo AM and Klionsky DJ: Autophagy fights disease through cellular self-digestion. Nature 451: 1069-1075, 2008 . 
21. Thumm M and Kadowaki T: The loss of Drosophila APG4/AUT2 function modifies the phenotypes of cut and Notch signaling pathway mutants. Mol Genet Genomics 266: 657-663, 2001.

22. Lapierre LR, Gelino S, Melendez A and Hansen M: Autophagy and lipid metabolism coordinately modulate life span in germline-less C. elegans. Curr Biol 21: 1507-1514, 2011.

23. Wang MC, O'Rourke EJ and Ruvkun G: Fat metabolism links germline stem cells and longevity in C. elegans. Science 322: 957-960, 2008

24. Palomero T, Sulis ML, Cortina M, Real PJ, Barnes K, Ciofani M, Caparros E, Buteau J, Brown K, Perkins SL, et al: Mutational loss of PTEN induces resistance to NOTCH1 inhibition in T-cell leukemia. Nat Med 13: 1203-1210, 2007.
25. Barth JM, Hafen E and Köhler K: The lack of autophagy triggers precocious activation of Notch signaling during Drosophila oogenesis. BMC Dev Biol 12: 35, 2012.

26. Wu X, Fleming A, Ricketts T, Pavel M, Virgin H, Menzies FM and Rubinsztein DC: Autophagy regulates Notch degradation and modulates stem cell development and neurogenesis. Nat Commun 7: 10533, 2016. 